\title{
Water-free Bonding of Corrugated Board
}

\author{
Astrid O. Glasenapp ${ }^{1 *}$, Maria Sundin ${ }^{1}$, Johanna Nordlinder ${ }^{2}$, \\ Jesper Berthold $^{1}$ and Johan Alfthan ${ }^{1}$ \\ ${ }^{1}$ RISE Bioeconomy, 16440 Kista, Sweden \\ ${ }^{2}$ The Swedish Patent- and Registration Office, 11441 Stockholm, Sweden
}

\begin{abstract}
The "water-free bonding of corrugated board" concept focuses on the development, waste management and market potential of a new corrugated board production method. It has earlier been shown that by integrating PLA into paper, certain mechanical properties of corrugated board papers can be enhanced. These enhanced papers have been used for producing corrugated board.

Corrugated board is usually produced by gluing the corrugated board paper layers with a starch suspension. This process is reducing the mechanical paper strength and is also energy consuming, as the water added by the starch suspension in the process has to be evaporated.

In this study, two new water-free joining techniques for corrugated board have been investigated: PLA-welding, which melts the inherent PLA of the paper to create a bond and using PLA as an adhesive. Both techniques have shown promising results and are recommended for further investigation, however, replacing starch glue with PLA seems to be a solution closer to the market.

For the material to fit in a future circular economy it is important that the waste is managed in a way that is sustainable for the environment and the society. Repulpability testing in combination with literature studies indicate that the new material would be possible to recycle, and that the new material could function in every step described in the EU Waste Framework Directive.
\end{abstract}

Keywords: corrugated board, PLA, gluing, circular economy

\section{Introduction and background}

\subsection{Material development}

The manufacturing of corrugated board has not changed a lot since the 1930s'. In 1908, a corrugator using the same principles as the ones that are in use today was invented. The usage and composition of the starch adhesive, which is used to glue the layers together, has been basically the same since 1935 .

The reason for using starch glue to join the layers together is due to its cost effectiveness, its pumpability and its ability to bond during high speed [1]. However, the starch glue bond does not tolerate high moisture and loses strength quickly when moist. Other polymeric materials are therefore sometimes added for applications where higher moisture resistance is needed, with the consequence that the costs increase [2].

The starch adhesive has another downside. When the adhesive dries, it shrinks and thereby pulls the liner and the fluting together. This is an undesired effect called washboarding [3], the uneven surface can cause printing problems, such as poor colour coverage [4]. 
Warp is another undesired effect connected to the manufacturing process. Warp is a curvature of corrugated board that occurs when each liner has a different moisture level, leading to different dimension changes when drying. This could for example depend on uneven moisture of the liner papers going into the machine, uneven grammage of the papers, or uneven application of the starch adhesive [5].

Corrugated board can show a behaviour called creep. Creep in corrugated board is caused by a constant load and it is accelerated by fluctuations in humidity [6]. This phenomenon is referred to as mechano-sorptive creep. The result of it is buckling and failure of corrugated board packaging [7].

Previous research has shown that by adding PLA to paper pulp and treating it with heat and pressure, the properties of the material can be manipulated. The temperature and pressure treatment is called activation of the PLA-paper. One of the improvements is a reduction in mechano-sorptive creep, which is proportional to the amount of PLA. Other affected properties are air permeability, z-strength and bending stiffness as well as the tensile and fracture properties [8]. It has been noted that the activation ideally should be carried out at a temperature below $220^{\circ} \mathrm{C}$ and at a pressure below $1 \mathrm{MPa}$, to avoid creating a brittle material. Benefits of adding PLA are most notable in papers made of recovered fibres [7], [9].

The addition of PLA in the paper increases the material cost [10], and the addition of heat and pressure also has to be considered from an economic perspective. Wickholm et al. (2012) [11] concluded that the heating time for the activation of the PLA-papers had to be shortened to decrease the energy cost. However, some energy increase can be compensated for by savings in other parts of the production. For example, dewatering is a part of the papermaking process which requires a lot of energy. By adding PLA to the paper, less water remains after the press section and thus less drying is required [11]. The effects on paper properties by the addition of PLA, pressure and temperature has been compiled in Table 1.

Table 1. Impact of pressure, temperature and PLA on the properties of the PLA-paper. Red indicates a negative impact, green a positive impact, and yellow no clear impact at either direction.

\begin{tabular}{|l|l|l|l|}
\hline & Pressure increase & $\begin{array}{c}\text { Temperature increase } \\
(\text { up to 180 }\end{array}$ & PLA increase \\
\hline Bending stiffness & & & \\
\hline Permeability & & & \\
\hline Mechanical properties* & & & \\
\hline Bulk (thickness) & & & \\
\hline Hygroexpansivity & & & \\
\hline Isocyclic creep stiffness & & & \\
\hline Cost & & & \\
\hline
\end{tabular}

*Tensile stiffness, tensile strength, tensile energy absorption, z-strength, critical tensile index, SCT

\subsection{Recycling}

Fibre box association (2015) [12] claims that corrugated board products had a global recovery rate of over $91 \%$ in 2012, making it the most recycled packaging material. After use, the corrugated board containers are collected, sorted and baled at the point of end-use or at recycling centres. They are then transported to the paper mill, broken up, and put into the repulper with 
water to form pulp. The pulp then goes through a row of different filtering and cleaning operations, before it is ready to be put back into the paper machine [12].

The repulping process shortens the average fibre length and the inter-fibre bonding strength becomes weaker. This result in weaker products with reduced bulk and stiffness compared to those made of virgin fibres. This means that fibres cannot be recycled indefinitely; the recovered pulp must be reinforced through mixing with new fibres [13].

A way of measuring the recyclability of a paper material is to test the repulpability, which is a measurement of how well the paper is converted back into pulp [14].

In the case of PLA, recycling can be done either in a chemical or in a mechanical process. However, implementation of this recycling process is less than ideal. PLA contaminates the waste stream of plastics, since it is difficult to sort out the different types of plastics [15].

In a study of PLA-paper, it was discovered that unactivated PLA-papers were completely repulpable. However, to achieve good performance, the papers need to be activated using heat and pressure. After that treatment, the paper was found to have a lower level of repulpability. Though with a PLA content up to $10 \%$, the treated material had a relatively good repulpability in cold water [16]. Composites containing higher levels of PLA (20\%) showed low repulpability in cold water, but the result might improve with higher temperatures or a different $\mathrm{pH}$ [8].

Another study investigated mechanical recycling of a composite with $70 \%$ cellulose fibers and $30 \%$ PLA. It was concluded that the grinded recyclate can be used as filler for PLA. Through mixing of PLA with grinded composite, the relatively high price could be lowered, and the technical properties manipulated, which could aid PLA in gaining market shares. For example, the tensile strength and the modulus for the PLA increased notably when composite recyclate was added. The possibility of recycling this mixture was tested by repeated injection moldings. The PLA with $20 \%$ filler could sustain its mechanical properties quite well for six cycles. A compound with a higher percentage of filling lost the technical properties much quicker [17]. Through experiments, the repulpability of the material has been tested as part of this project. Even though the literature gives some indications on what the recycling possibilities for the new corrugated board might look like, the effect from the material joining is still unexplored and must be further investigated.

\section{Methods}

\subsection{Strategy for experiments}

Prior to the laboratory experiments, an idea generating session was conducted with employees at RISE and students. The goal was to generate as many ideas as possible on the theme "joining", which could inspire the choice of joining techniques for the corrugated board.

With support from the idea generation session, the experiments were planned. The strategy for the laboratory experiments was to find the most relevant idea, try it, and then evaluate if another idea would need to be tried.

\subsection{Equipment}

For heating and pressing the papers, the hydraulic laboratory press Polystat $200 T$ was used. It allows a maximum press force of $200 \mathrm{kN}$ and a maximum temperature of $300^{\circ} \mathrm{C}$.

\subsection{Materials}

The papers used had been manufactured on the RISE pilot paper machine FEX during earlier projects at RISE Bioeconomy. The papers contain different amounts of PLA and are made of different kinds of fibres as can be seen in Table 2. 
Table 2. Papers used in the project.

\begin{tabular}{|c|c|c|c|}
\hline Name & PLA-content $[\%]$ & Pulp type & Grammage $\left[\mathrm{g} / \mathrm{m}^{2}\right]$ \\
\hline $\mathbf{A}$ & 0 & Recovered pulp & 112 \\
\hline B & 5 & Recovered pulp & 112 \\
\hline $\mathbf{C}$ & 10 & Recovered pulp & 112 \\
\hline $\mathbf{D}(\mathbf{K})$ & 0 & Industrially produced softwood kraft pulp & 100 \\
\hline $\mathbf{E}(\mathbf{K})$ & 10 & Industrially produced softwood kraft pulp & 100 \\
\hline $\mathbf{F}(\mathbf{K})$ & 20 & Industrially produced softwood kraft pulp & 100 \\
\hline
\end{tabular}

The PLA fibers used in this project are of the type Ingeo 6100D from NatureWorks. It is made from dextrose from field corn and it is semi-crystalline. Its glass transition temperature is $55-60^{\circ} \mathrm{C}$ and the melting temperature is $165-180^{\circ} \mathrm{C}$. The films used are BCFD films manufactured by Naturefirst, manufactured from Ingeo fibres from NatureWorks.

\subsection{Procedure and variables}

The experiments have been conducted by using a hot press to investigate the impact on the bond when changing a set of variables. The examined variables are temperature, pressure, PLA-amount in paper, amount of added PLA, pressure time and heating time.

\subsection{Recycling}

For testing the recycling properties of the material, five different kinds of samples were manufactured, following a standard developed by Fiber Box Association (2013) [18]. The process included mixing the samples with water, sifting the mix and drying and weighing the remainder to calculate its ratio to the start weight. According to the standard used, the repulpability percentage should be above $80 \%$ in order for the treated material to be acceptable from a recycling perspective. Even though the standard has not been followed strictly, this number will be used as an indication to relate the test results to.

\section{Results}

Two different types of joining techniques have been investigated. Using only the PLA-content of the paper to weld the components did generate a weaker bond. Adding extra PLA between the papers as an adhesive generated a stronger bond. The strength of the bonds was in a first step evaluated continuously through peeling the joint papers apart by hand. If fibre tear occurred, the bond was deemed as strong enough. In addition to this, z-testing has been conducted to get exact numbers on the strength of the bond. The result from these are described later in this chapter. From the laboratory experiments some tendencies has been discovered regarding the bonding properties in relation to the changing of variables. The tendencies need further testing to be scientifically confirmed.

\subsection{Welding PLA-papers}

For the experiments where the papers joined by PLA welding, it was observed that even the strongest bonding result achieved was easy to peel. It was also noted that both components to be welded needed to contain PLA.

Regarding the variable impact on the bond, several tendencies have been noted (Table 3 ). Through a combination of those tendencies and the information found in literature, an upper and a lower limit for the different variable could be found. These limits apply for the specific 
PLA-papers manufactured by RISE Bioeconomy, of an area of $529 \mathrm{~cm}^{2}$ and for two sheets being welded together.

Table 3. Limits of variables for welding PLA-papers.

\begin{tabular}{|c|c|c|}
\hline Variable & Lower limit & Upper limit \\
\hline Temperature & $\begin{array}{c}\text { Temperature needs to be above } \\
\text { melting point for semi crystalline } \\
\text { PLA. }\end{array}$ & $\begin{array}{l}\text { The temperature should not exceed } 230^{\circ} \mathrm{C} \text { since this } \\
\text { affects the properties of the paper [7]. }\end{array}$ \\
\hline Pressure & $\begin{array}{c}\text { The pressure applied should be } \\
\text { above } 95 \mathrm{kPa} \text { (Observed from trial } 5 \\
\text { and } 8 \text { ) }\end{array}$ & Up to $1 \mathrm{MPa}$ (Wickholm, et al., 2009). \\
\hline Time & $\begin{array}{l}1 \text { minute of heating and pressure is } \\
\text { enough time to join papers } \\
\text { containing } 10 \% \text { PLA. }\end{array}$ & No upper limit has been observed. \\
\hline PLA content & $\begin{array}{l}\text { The PLA content needs to exceed } \\
5 \% \text { for these sheets to bond. }\end{array}$ & $\begin{array}{c}\text { No upper limit has been observed from a strict } \\
\text { bonding perspective. However, other factors will } \\
\text { have impact on this. }\end{array}$ \\
\hline
\end{tabular}

\subsection{PLA as an adhesive}

For the experiments where the papers have been joined using extra PLA between the papers, it was observed that fibre tear occurred for all experiments where the PLA had melted completely. However, the method used for spreading the PLA created an uneven bonding. To avoid the uneven bonds, several experiments were carried out using PLA films. Those bonds were strong and even. However, the PLA-films were quite thick compared to the papers.

The variables impact differed from the experiments of welding PLA-papers. The temperature used was the same, but the pressure could be eliminated entirely. The process required slightly longer heating time, but the sheets did not need to contain PLA. Low amounts of PLA still created strong bonds. The results for the variables are presented in Table 4.

Table 4. Limits of variables for using PLA as an adhesive.

\begin{tabular}{|l|l|l|}
\hline Variable & Lower limit & Upper limit \\
\hline Temperature & \multicolumn{1}{|c|}{ The same temperatures are used as for welding PLA-papers (see Table ) } \\
\hline Pressure & \multicolumn{2}{|c|}{ No pressure needed } \\
\hline Time & $\begin{array}{l}\text { 1 minute seems to be too short to create } \\
\text { a bond. A heating time of 2 minutes is } \\
\text { enough to create a bond. }\end{array}$ & No upper limit has been observed. \\
\hline Added PLA $\left[\mathbf{g} / \mathbf{c m}^{2}\right]$ & 0.00043 & No upper limit has been observed. \\
\hline
\end{tabular}

\subsection{Verifying the results}

Table 5. Bonding strength testing.

\begin{tabular}{|l|l|l|}
\hline \multicolumn{1}{|c|}{ Sample } & \multicolumn{1}{|c|}{$\begin{array}{c}\text { Total average } \\
{[\mathbf{k P a}]}\end{array}$} & $\begin{array}{c}\text { Standard deviation } \\
{[\mathbf{k P a}]}\end{array}$ \\
\hline Only tape & 1470.7 & 34.1 \\
\hline Paper strength, recovered fibres, 0 \% PLA & 549.0 & 29.7 \\
\hline Paper strength, recovered fibres, 10 \% PLA, unactivated & 450.6 & 10.1 \\
\hline Paper strength, recovered fibres, 10 \% PLA, activated & 688.4 & 27.5 \\
\hline PLA film, recovered fibres, 0 \% PLA in the paper & 661 & 27.9 \\
\hline PLA film, virgin fibres, 20 \% PLA in the paper, activated & 816.3 & 40.7 \\
\hline PLA welding, virgin fibres, 20 \% PLA, activated & 790.3 & 76.3 \\
\hline PLA welding, virgin fibres, 10 \% PLA, activated & 129.9 & 22.4 \\
\hline PLA welding, recovered fibres, 10 \% PLA, activated & 310.1 & 158.2 \\
\hline
\end{tabular}


To investigate the strength of the bonding, a series of bonding strength testing was conducted. The testing was done with the aid of an L\&W ZD tensile tester, which attaches an adhesive tape on each side of the test sample, or in this case the two bonded components, and then measures the force needed to cause a separation.

Samples to test were manufactured by cutting pieces of joined sheets to the measurements of $65 \times 160 \mathrm{~mm}^{2}$ and then taping the short edges of three such pieces together, resulting in a $65 \times 480$ $\mathrm{mm}^{2}$ sample. For each such sample, the separation force was measured 6 times to investigate differences within the same sample.

The strength of the paper itself was tested to be able examine whether the bond or the paper has broken. Also, the strength of the tape was tested as a reference to find the maximum value and an average deviation. The average results from the bonding strength testing are presented in Table 5 .

\subsection{Recycling}

Table 6 shows the result from the repulpability testing. Apart from the PLA-free reference, the samples made from virgin pulp, containing 10\% PLA, and the samples made of recovered pulp, using 10\% PLA in the form of film, passed the limit set by the standard. The PLA-paper containing $20 \%$ PLA did, in line with what has been indicated in previous studies, not meet up to the standard. The welded sample containing 10\% PLA performed worst of all and was far away from meeting the standard, something that contradicts the literature study.

Table 6. Result from the repulpability testing.

\begin{tabular}{|c|c|c|}
\hline Sample & Repulpability (\%) & Comment \\
\hline Recovered pulp, 0\% PLA in paper, 10\% PLA in total & $81.8 \%$ & PLA-film as adhesive \\
\hline Virgin pulp, 20\% PLA & $67.4 \%$ & Welded \\
\hline Virgin pulp, 10\% PLA & $88.5 \%$ & Welded \\
\hline Recovered pulp, 10\% PLA & $57.5 \%$ & Welded \\
\hline Reference, Recovered pulp, 0\% PLA & $99.7 \%$ & Unactivated \\
\hline
\end{tabular}

\section{Discussion}

\subsection{Material development}

The material development phase has generated two different concepts for joining the papers together with PLA: PLA-welding where the inherent PLA in the paper is melted and pressed to join the papers together, and PLA as an adhesive where the papers are joined by adding extra PLA and melting it between them.

It is desirable to lower the temperature required in the process. Since the PLA used in this project has a high melting point, an energy consuming high temperature has been required. According to Barla (2003) [19] a temperature of $150{ }^{\circ} \mathrm{C}$ is applied in the corrugated board production already today, but this is not optimal from an environmental and economic perspective. This impact could probably be reduced through usage of a PLA-type with a lower melting point. According to theory of plastic welding, amorphous polymers only need to be heated to their glass transition temperature, which is around $55-60{ }^{\circ} \mathrm{C}$ for some PLA-types. Therefore, changing to an amorphous PLA rather than a semi-crystalline might have a positive impact. Switching PLA type might however affect the material properties. 
Later on in the development process, pin-adhesion tests could be used to test the bonding strength in corrugated board, compared to the general bonding strength being tested early on in the development.

A bond that is strong enough to meet todays' industry standard will probably not be achieved by using PLA-welding. However, it could be questioned whether this strength is truly required in all applications. Also, the fact that the individual layers can be easily separated could be an advantage in some applications.

The effect of different pressures on the bonding strength needs to be considered. The corrugating machine would need to be able to apply pressure in the points where the fluting meets the liner, while avoiding damaging the fluting by adding pressure in the wrong areas. However, according to Barla (2003) [19] the paper speed is lower and the risk of deformations higher when similar techniques are used in the industry. From that aspect, the welding technique might be less suitable.

Adding PLA between the layers creates a stronger bond than the PLA-welding technique. This method achieves the desired fibre tear. The strength of the bond was measured; however the data do not reveal the actual strength of the bond. Even when using the strongest available papers, the paper teared before the bond broke. Later in the development process, pin-adhesion tests could be used to test the bonding strength in corrugated board, compared to the general bonding strength being tested early on in the development.

In production the most viable solution would probably be to melt PLA and use the conventional method for glue application. The prolonged time compared to welding PLA-papers together might be caused by several different factors. The amount and distribution of the PLA might affect these numbers. One factor to consider is that paper act as an insulator, hampering the heating process. Through applying melted PLA with the conventional glue application process, it would be possible to bypass this obstacle.

However, the most time-consuming part is still the activation of the paper. Earlier projects have first heated the paper for 4 minutes and then heated and pressed them for the same amount of time. Hence, shortening this time should be more important than shortening the bonding time. Generally bonding with PLA could potentially reduce the energy consumption of the corrugated board production process substantially because there is no need to evaporate water when the thermoplast PLA could substitute the starch suspension used today.

\subsection{Recycling}

The repulpability testing was conducted according to a standard method, and it was decided to use the same conditions for all samples in order to be able to compare the results. In laboratory environment, as well as in industry, it is possible to alter some variables to try to increase the degree of material being repulped. This could for example be done by using warmer water, different $\mathrm{pH}$ levels, longer times or a higher rpm for the blender. The repulpability tests should also preferably be repeated in order to confirm the results.

In the existing Swedish waste infrastructure, recycling is the most common way of handling corrugated board waste with a $91 \%$ rate of recycling. Since the PLA-papers are hard to distinguish from regular paper, the ideal solution would be to develop a material that can be circulated together with regular corrugated board within the existing waste management infrastructure. The results from the repulpability tests indicate that this is possible, as long as the percentage of PLA is not too high.

When comparing the results, it is important to note that the reference samples were untreated and unglued. The reference could have been containing starch glue, however, due to resource limitations no such reference was produced. 
The results from the repulpability testing were somewhat surprising. The fact that the recovered, welded, samples with $10 \%$ PLA performed so much worse than the corresponding samples made out of virgin pulp was surprising. On the positive side, the samples using PLA film as an adhesive did perform better than expected. The tests show that using PLA as an adhesive would generate a material that is possible to repulp, which would be a very important property for getting the material out on the market. The next step would be to produce new papers out of the recyclate and investigate its properties.

\section{Conclusion}

This study aims to answer the question whether PLA-paper could be converted into corrugated board using a dry process. The result indicates that this would be possible by either using PLA welding or PLA as an adhesive. The PLA welding technique did generate a bond, but not strong enough to fulfill the conventional requirements for bonding corrugated board together. When adding extra PLA between the papers as an adhesive the bond instantly became stronger and fiber tear occurred. The two joining techniques have different properties, thus which joining technique to select depends on the application. More investigations are needed to optimize the bonding strength while using PLA as an adhesive. Repulping trials showed that the recycling of the material is in general possible but more investigation is needed. Further is PLA just one option for a thermoplast used instead of a starch suspension for bonding of corrugated board, other thermoplasts could be tested. This concept could save energy in corrugated board production as there is no need to evaporate water from a starch suspension.

\section{Acknowledgements}

The project was part of the TechMark arena 2017, financed by Skogsindustrins Forskningsstiftelse and Sundblad stiftelsen. Their financial support is highly acknowledged. Kerstin Johansen and Renee Weever from Linköping University are thanked for fruitful co-operation.

\section{References}

[1] Tweede D, Selke SEM. Cartons, Crates and Corrugated Board: Handbook of Paper and Wood Packaging Technology. Lancaster, Pennsylvania: DEStech Publications, Inc., 2005.

[2] Östlund S. Manufacturing of paperboard and corrugated board packages - Converting operations: printing, die-cutting, folding, gluing, deep-drawing. Stockholm: Kungliga tekniska högskolan, 2011.

[3] Wendler SD. Washboarding of Corrugated Cardboard 2006. Melbourne, Australia: Royal Melbourne Institute of Technology.

[4] Carlson D. Corrugating defect terminology 1988; 5th ed. Atlanta: TAPPI.Carlson, 1988.

[5] Jönsson G. Corrugated Board Packaging 1999; Second edition ed. Cornwall: Pira International.

[6] Mark RE. Handbook of physical and mechanical testing of paper and paperboard 1983; vol 2. New York: Marcel Dekker.

[7] Pötzsch S. Influence of PLA on the mechanical properties of paper materials 2015; Stockholm: KTH Royal Institute of Technology.

[8] Wickholm K, Mäkelä M. Kill that Creep - A novel approach for drastically reduced mechanosorptive creep of paper 2009; Stockholm: Innventia.

[9] Glasenapp A, Pötzsch S, Alfthan J, LindströmL and Berthold F. DuraWell-Novel approache to enhance the moisture resistance of corrugated board 2017; Lausanne $28^{\text {th }}$ IAPRI World Symposium on Packaging.

[10] Lim LT, Auras R and Rubino M. Processing technologies for poly(lactic acid). Progress in Polymer Science 2008; 33(8), pp. 820-852.

[11] Wickholm K, Waljanson A and Vomhoff H. I-bulk - concept verification 2012; Stockholm: Innventia. 
[12] Fibre box association. Fibre box handbook 2015; 23 ed. U.S.A.: Fibre box association.

[13] Kirwan MJ. Handbook of Paper and Paperboard Packaging Technology 2013; 2nd ed. Chichester: John Wiley \& Sons, Ltd.

[14] Merriam-Webster [Online] Available at: https://www.merriam-webster.com/dictionary/Accessed 30 January 2017.

[15] Cstro-Aguirre E. Poly( lactic acid) - Mass production, processing, industrial applications, and end of life 2016; Advanced Drug Delivery Reviews, Volym 107, pp. 333-366.

[16] Karpenja T, Lorentzon A and Wickholm K. Sustainability Aspects in Waste Management of Biocomposites 2013; Espoo, 26th IAPRI Symposium on Packaging.

[17] Åkesson D, Vrignaud T, Tissot C and Skrifvars M. Mechanical recycling of PLA filled with a high level of cellulose fibers. Journal of Polymers and the Environment 2016; 24(3), pp. 185-195.

[18] Fibre box association, 2015. Fibre box handbook. 23 ed. U.S.A.: Fibre box association.

[19] Barla V. Cold corrugating process. TAPPSA Journal. 2003. 